\section{Should All Elderly Women Receive Bisphosphonates to Prevent Osteoporotic Fractures?}

\section{THE "PRO" SIDE}

The average life expectancy of Canadians is increasing and is now 83 years for women and 78 for men. ${ }^{1}$ Given this longer lifespan, it is important for health care providers to offer education and create action plans that will help people to achieve the highest quality of life possible as they age. Hip and vertebral fractures result in disability and death, and the mortality rate among people with hip fractures is 23\% in the first year after the fracture. ${ }^{2}$ At the age of 50 , a woman has a $40 \%$ chance of experiencing a hip, vertebral, or wrist fracture during her remaining lifetime. ${ }^{3}$ To put the risk of fracture into perspective, the 1 in 6 lifetime risk of hip fracture for women is greater than their 1 in 9 lifetime risk of breast cancer. ${ }^{4}$ Because the risk of fracture and its associated morbidity and mortality increase with age, there is a growing need to pay particular attention to the treatment and prevention of osteoporotic fractures with aging.

In support of the statement that "all elderly women should receive bisphosphonate therapy to prevent osteoporotic fractures", consider that osteoporosis is present in 1 of every 4 women over 50 years of age, and this prevalence increases exponentially to over two-thirds of women aged 90 years or older. ${ }^{5}$ Preventing the initial fracture is particularly important, since 1 in 4 women with a new vertebral fracture will have another fracture within 1 year. $^{6}$ As such, there may be a benefit to treating all women 70 years and older to prevent fractures and/or to prevent osteoporosis. In a survey study of 194 women older than 75 years, $80 \%$ said they would rather be dead (utility $=0$ ) than experience the loss of independence and reduced quality of life that results after hip fracture and subsequent admission to a nursing home. ${ }^{7}$ In a study of Ontario residents 50 years of age or older who were living at home before hospital admission for treatment of hip fracture, 10\% went to another hospital following discharge, $17 \%$ to a long-term care facility, and $27 \%$ to rehabilitation care. ${ }^{8}$ Furthermore, osteoporotic hip fractures result in more hospital bed days than stroke, diabetes mellitus, and heart attack combined. ${ }^{2}$ Intervening before a fracture occurs is key, because after a fracture has occurred, it is too late to prevent the fracture cascade and, by definition, a patient with an osteoporotic fracture has weak bone and is at high risk of another fracture. It is far better to identify those who need preventive therapy (for example, all women 70 years and older) early.
All of the bisphosphonates, except etidronate, have a statistically significant impact on fracture reduction within 1 year of treatment initiation. ${ }^{9}$ Therefore, every woman 70 years of age or older who expects to live more than 1 year and has a desire to reduce her risk of fracture should consider bisphosphonate therapy, along with sufficient vitamin D (1000-2000 IU/day) and calcium (1000-1200 mg elemental calcium per day via supplements and dietary sources combined). ${ }^{9}$ In various prospective clinical trials, bisphosphonates, in particular alendronate, risedronate, and zoledronic acid, have reduced vertebral, nonvertebral, and hip fractures in study populations with an average age of 68 years or older at the time of enrolment. ${ }^{10-12}$ Other therapies, such as calcitonin, denosumab, hormone therapy with estrogen and progesterone, raloxifene, and teriparatide, have led to reductions in fracture risk. ${ }^{13}$ However, bisphosphonates are among the most studied therapies for fracture prevention, and they are less expensive than other agents. Definitive pharmacoeconomic evaluations showing which agent is the most cost-effective are still lacking, but use of bisphosphonates to reduce fractures and (potentially) death would seem a reasonable treatment choice.

Using a threshold age of 70 years to identify women eligible for bisphosphonate therapy may have some merit when the risk of fracture in this age group is considered. The FRAX 10-year absolute fracture risk calculator ${ }^{14}$ and the CAROC (Canadian Association of Radiologists and Osteoporosis Canada) 10-year fracture risk calculator ${ }^{13}$ show that the risk of a fracture increases exponentially with age for both women and men. Although opinions vary regarding the definitions of risk levels, most agree that a 10-year fracture risk below $10 \%$ represents low risk, a risk of $10 \%-20 \%$ is moderate, and a risk above $20 \%$ is high. A healthy 70 -year-old woman of average height $(165 \mathrm{~cm})$ and weight $(57 \mathrm{~kg})$ with no other risk factors has an $11 \%$ risk of major osteoporotic fracture in the next 10 years, according to the FRAX calculator (i.e., a moderate risk, as defined by the CAROC tool), and the presence of any additional risk factors would push her risk higher. An "average" 80 -year-old woman would have a FRAX result of greater than $20 \%$ risk of major osteoporotic fracture. Treatment with a bisphosphonate would be expected to reduce the risk for these women to about $6 \%$ and $10 \%$, respectively, given the relative risk reduction of about $50 \%$ reported in most clinical trials. Targeting elderly women (i.e., 80 years or older) as a group would seem to be an effective approach, since they are already at high risk, and additional risk factors and morbidities would only serve to elevate the risk further. Osteoporosis is underrecognized, and $80 \%$ of patients with a history of fractures do not receive osteoporosis therapy. ${ }^{2}$ Therefore, using an age-specific 
trigger to initiate bisphosphonate treatment may be an effective approach.

The Hip Intervention Program (HIP) Study enrolled 3866 women aged 80 years or older who had one nonskeletal risk factor or low bone mineral density (BMD) and 5445 women aged 70-79 years with a very low $\mathrm{T}$ score $(-4)$ or a low $\mathrm{T}$ score (-3) combined with a nonskeletal risk factor (where the $\mathrm{T}$ score refers to the number of standard deviations above or below the mean BMD for a healthy 30-year-old adult of the same sex and ethnicity as the patient). Overall, compared with placebo, women who received risedronate had a 30\% relative risk reduction (RRR) for hip fracture $(95 \%$ confidence interval [CI] $10 \%-40 \%$; number needed to treat [NNT] 91). Within the study group of participants 70-79 years of age, there was an even greater magnitude of effect (RRR 40\%, 95\% CI $10 \%-60 \%$; NNT 77). ${ }^{15}$ In addition to a reduction in fracture risk, some studies have also demonstrated a reduction in mortality risk. In a study comparing zoledronic acid $5 \mathrm{mg}$ IV once yearly with placebo infusion in patients treated within 90 days after surgical repair of a low-trauma hip fracture (mean age 74.5 years), the mortality rate decreased by $28 \%$ (95\% CI 7\%-44\%; NNT 28). ${ }^{16}$ In the same study, zoledronic acid also reduced the risk of a new clinical fracture (RRR 35\%, 95\% CI 16\%-50\%; NNT 19). ${ }^{16}$

Considering treatment on the basis of age, with or without use of a risk assessment tool, will help to identify women at high risk who might not otherwise be identified. A BMD measurement to identify women with $\mathrm{T}$ score below a certain threshold (e.g., below -2.5) would yield better targeting and reduce the NNT. However, this approach comes with additional costs and inconvenience associated with BMD measurements, as well as associated concerns regarding inaccuracies of the measurement tool. For example, standards recommend that serial BMD measurements be done by the same technologist on the same machine, an indication that BMD accuracy is problematic. ${ }^{17,18}$

In many trials, there have been no particularly notable differences in adverse effects between bisphosphonates and placebo. For example, even in very elderly patients (older than 80 years), the main difference in adverse effects was a nonsignificant $2.5 \%$ higher risk of any upper gastrointestinal adverse event with risedronate compared with placebo. ${ }^{19}$ Other adverse effects, such as osteonecrosis of the jaw and atypical fracture, may be associated with long-term use of bisphosphonates, but these are very rare and do not seem to be independently associated with age..$^{20,21}$

Although zoledronic acid is the only bisphosphonate with prospective studies showing reductions in both fracture and mortality rates, these results may indicate that other bisphosphonates have similar effects; however, studies are required to demonstrate this effect. A fracture can be devastating, particularly if it affects the hip. All patients 70 years of age and older should undergo an assessment of absolute fracture risk and should ensure optimal intake of calcium and vitamin D and appropriate diet and exercise for bone health. In addition, bisphosphonate therapy should be considered to reduce the risk of fracture, the potential for disability and dependence, and, in some cases, the risk of death.

\section{References}

1. Deaths. Ottawa (ON): Statistics Canada; [modified 2011 Jul 5; cited 2011 Oct 20]. Available from: www.statcan.gc.ca/daily-quotidien/100223/ dq100223a-eng.htm

2. Facts and statistics. Toronto (ON): Osteoporosis Canada; 2011 [cited 2011 Oct 20]. Available from: www.osteoporosis.ca/index.php/ci_id/8867/ la id/1.htm

3. Melton LJ 3rd, Chrischilles EA, Cooper C, Lane AW, Riggs BL. Perspective: How many women have osteoporosis? J Bone Miner Res 1992;7(9): 1005-1010.

4. Cummings SR, Black DM, Rubin SM. Lifetime risks of hip, Colles', or vertebral fracture and coronary heart disease among white postmenopausal women. Arch Intern Med 1989;149(11):2445-2448.

5. Kanis JA. WHO Technical Report: Assessment of osteoporosis at the primary health care level. Summary report of a WHO Scientific Group. Sheffield (UK): University of Sheffield; 2007.

6. Lindsay R, Burge RT, Strauss DM. One year outcomes and costs following a vertebral fracture. Osteoporosis Int 2005;16(1):78-85.

7. Salkeld G, Cameron ID, Cumming RG, Easter S, Seymour J, Kurrle SE, et al. Quality of life related to fear of falling and hip fracture in older women: a time trade off study. BMJ 2000;320(7231):341-346.

8. Osteoporosis fractures: incidence and impact. Toronto $(\mathrm{ON})$ : Institute for Clinical Evaluative Sciences; 1998 [cited 2012 Jan 16]. P. 143-156. Available from: www.ices.on.ca/WebBuild/site/ices-internet-upload/file_ collection/Arth-chp8-.pdf

9. Miller P. Analysis of 1-year vertebral fracture risk reduction data in treatments for osteoporosis. South Med J 2003;96(5):478-485.

10. Cranney A, Wells G, Willan A, Griffith L, Zytaruk N, Robinson V, et al.; Osteoporosis Methodology Group and The Osteoporosis Research Advisory Group. Meta-analyses of therapies for postmenopausal osteoporosis: II. Meta-analysis of alendronate for the treatment of postmenopausal women. Endocrine Rev 2002;23(4):508-516.

11. Cranney A, Tugwell P, Adachi J, Weaver B, Zytaruk N, Papaioannou A, et al.; Osteoporosis Methodology Group and The Osteoporosis Research Advisory Group. Meta-analyses of therapies for postmenopausal osteoporosis: III. Meta-analysis of risedronate for the treatment of postmenopausal osteoporosis. Endocrine Rev 2002;23(4):517-523.

12. Deeks ED, Perry CM. Zoledronic acid: a review of its use in the treatment of osteoporosis. Drugs Aging 2008;25(11):963-986.

13. Papaioannou A, Morin S, Cheung AM, Atkinson S, Brown JP, Feldman S, et al.; Scientific Advisory Council of Osteoporosis Canada. 2010 clinical practice guidelines for the diagnosis and management of osteoporosis in Canada: summary. CMAJ 2010;182(17):1864-1873.

14. FRAX: WHO risk assessment tool: calculation tool [Canada version]. Sheffield (UK): World Health Organization Collaborating Centre for Metabolic Bone Diseases; [cited 2011 Oct 24]. Available from: www.shef.ac.uk/FRAX/tool.jsp?country=19

15. McClung MR, Geusens P, Miller PD, Zippel H, Bensen WG, Roux C, et al.; Hip Intervention Program Study Group. Effect of risedronate on the risk of hip fracture in elderly women. N Engl J Med 2001;344(5):333-340.

16. Lyles KW, Colón-Emeric CS, Magaziner JS, Adachi JD, Pieper CF, Mautalen C, et al.; Horizon Recurrent Fracture Trial. Zoledronic acid and clinical fractures and mortality after hip fracture. N Engl J Med 2007; 357(18):1799-1809.

17. Laskey MA, Flaxman ME, Barber RW, Trafford S, Hayball MP, Lyttle KD, et al. Comparative performance in vitro and in vivo of Lunar DPX and Hologic QDR-1000 dual energy x-ray absorptiometers. Br J Radiol 1991; 64(767):1023-1029.

18. Baim S, Wilson CR, Lewiecki EM, Luckey MM, Downs RW Jr, Lentle BC. Precision assessment and radiation safety for dual-energy $\mathrm{x}$-ray absorptiometry: position paper of the International Society for Clinical Densitometry. J Clin Densitom 2005;8(4):371-378.

19. Boonen S, McClung MR, Eastell R, El-Hajj Fuleihan G, Barton IP, Delmas P. Safety and efficacy of risedronate in reducing fracture risk in osteoporotic women aged 80 and older: implications for the use of antiresorptive agents in the old and oldest old. J Am Geriatr Soc 2004;52(11):1832-1839. 
20. Zhang J, Saag KG, Curtis JR. Long-term safety concerns of antiresorptive therapy. Rheum Dis Clin North Am 2011;37(3):387-400.

21. Park-Wyllie LY, Mamdani MM, Juurlink DN, Hawker GA, Gunraj N, Austin PC, et al. Bisphosphonate use and the risk of subtrochanteric or femoral shaft fractures in older women. JAMA 2011;305(8):783-789.

Alan Low, BSC(Pharm), PharmD, RPh, ACPR, FCSHP, CCD

Faculty of Pharmaceutical Sciences

University of British Columbia

Vancouver, British Columbia

\section{THE "CON" SIDE}

The definition of evidence-based health care has for a long time been "the integration of best research evidence with clinical expertise and patient values". ${ }^{1}$ A statement such as "all elderly women should receive bisphosphonates" is similar to many of the so-called evidence-based, yet fundamentally paternalistic, recommendations found in the plethora of recent guidelines for managing chronic disease states. A colleague and I recently showed that 5 major Canadian chronic disease state guidelines were essentially devoid of commentary about incorporating patient values into decision-making and that these guidelines do not contain sufficient evidence to properly engage patients in the concept of shared, informed decision-making. ${ }^{2}$ Combined, these documents contained about 90000 words, and only 99 of those words had anything to do with patient values. An equally important issue when it comes to clinicians making decisions is the fact that only about $10 \%$ of recommendations in guidelines are based on the highest level of evidence, typically randomized controlled trials, whereas fully half of the recommendations are based on opinion. ${ }^{3,4}$ This information alone should give individual clinicians and patients great latitude to not just blindly follow guidelines.

Interestingly, and despite or perhaps because of the guidelines, "almost three-quarters of all women initiating osteoporosis drug therapy regardless of the medication received are no longer adherent with treatment 12 months following therapy initiation, and almost one-half have discontinued such therapy by this time." ${ }^{5}$ This nonadherence is not because these $75 \%$ of the patients experienced adverse effects, as most of these medications are relatively well tolerated. I would suggest that much of this "intelligent nonadherence" stems from clinicians following guidelines and stating "I think you need a bisphosphonate because you have osteoporosis", rather than taking the time to discuss the benefits and harms of a medication and, if the patient desires, letting her decide if she wishes to take the medication, with us health care professionals being supportive, regardless of the decision.

Overall, drug therapy for osteoporosis (primarily bisphosphonates), when given in clinical trials, reduces the frequency of nonvertebral and wrist fractures by $20 \%$ each, of hip fractures by
$25 \%$, and of vertebral fractures by $50 \%$ over a period of $2-3$ years. The evidence for longer treatment is limited. ${ }^{6}$

To use these relative numbers in a meaningful way, one needs to know the baseline risks. In the meta-analysis cited above, ${ }^{6}$ the average baseline risks for these types of fracture were roughly $10 \%$ (nonvertebral), 3\% (wrist), 2\% (hip), and 10\% (vertebral). Applying the relative risk reductions to these baseline risks leaves us with absolute benefits for nonvertebral fractures (which include hip and wrist fractures) of about 2\% (i.e., $20 \%$ of $10 \%$ ) and for vertebral fractures (not all clinically important), $5 \%$ (i.e., $50 \%$ of $10 \%$ ). A complicating factor is that these baseline risks come from combining both primary and secondary prevention trials, so the numbers are likely lower and higher for primary and secondary prevention, respectively.

Because the underlying risk can greatly influence the magnitude of absolute benefit with bisphosphonates, clinicians could use risk assessment tools to help in their decisions. According to the FRAX mathematical models, a 70-year-old woman may have a 10-year fracture risk ranging anywhere from 5\% to $90 \%$, depending on her weight, bone mineral density, and the absence or presence of 6 risk factors. ' That knowledge alone should clearly show that "all elderly women" should not automatically be put on a bisphosphonate. However, one also has to add into the mix the issue of adverse effects and the cost of these agents, both of which will influence a patient's decision.

An important issue missing from the statement about what "all elderly women" should do is the fact that the majority of fractures, along with other injuries, are caused by falls. In fact, one-third of people over age 65 fall every year. ${ }^{8}$ A Cochrane review ${ }^{9}$ showed that exercise-based programs reduce the risk of falls by $20 \%$ to $35 \%$, and a recent Australian trial showed a roughly $40 \%$ reduction in falls and injuries with improvements in drug use via a medication review program. ${ }^{10}$ As health care providers and knowledge brokers, pharmacists have a lot to offer patients before the addition of drug therapy is even discussed.

So, if it's inappropriate to prescribe bisphosphonates for all elderly women, what should they be offered to prevent osteoporotic fractures?

- $\quad$ Exercise-based programs, which should have benefits over and above fall prevention

- A thorough review of all medications and an attempt to stop or reduce the dose of all drugs in general, but especially those with adverse effects on the central nervous system and those that lower blood pressure and glucose below the levels required to stand upright

- Information about the potential benefits and harms of therapy and testing, followed by support for each patient's ultimate decision

- A bone mineral density measurement only if they would consider taking a drug for fracture prevention

In addition, once a decision has been made to use a bisphosphonate, women should be told that further re-measurement of bone mineral density can only be misleading. ${ }^{11,12}$

In conclusion, any definitive statement suggesting that "all patients" should do some specific thing fundamentally flies in the 
face of the tenets of evidence-based health care. That is why it is easy for me to take the "Con" side of this particular Point Counterpoint debate.

\section{References}

1. Sackett DL, Straus SE, Richardson WS, Rosenberg W, Haynes RB. Evidence-based medicine: how to practice and teach EBM. 2nd ed. Edinburgh (Scotland): Churchill Livingstone; 2000.

2. McCormack JP, Loewen P. Adding "value" to clinical practice guidelines. Can Fam Physician 2007;53:1326-1327, 2001:e1-2001:e8.

3. Lee DH, Vielemeyer O. Analysis of overall level of evidence behind Infectious Diseases Society of America practice guidelines. Arch Intern Med 2011;171(1):18-22.

4. Tricoci P, Allen JM, Kramer JM, Califf RM, Smith SC Jr. Scientific evidence underlying the ACC/AHA clinical practice guidelines. JAMA 2009;301(8):831-841.

5. Weycker D, Macarios D, Edelsberg J, Oster G. Compliance with drug therapy for postmenopausal osteoporosis. Osteoporosis Int 2006;17(11):1645-1652.

6. Hopkins RB, Goeree R, Pullenayegum E, Adachi JD, Papaioannou A, Xie $\mathrm{F}$, et al. The relative efficacy of nine osteoporosis medications for reducing the rate of fractures in post-menopausal women. BMC Musculoskelet Disord 2011;12:209.

7. Canada - the probabilities of a major osteoporotic fracture in women. Sheffield (UK): World Health Organization Collaborating Centre for Metabolic Bone Disease; [cited 2011 Sep 15]. Available from: www.shef.ac.uk/FRAX/charts/Chart_CA_ost_wom_bmd.pdf
8. Tinetti ME. Clinical practice. Preventing falls in elderly persons. $N$ Engl J Med 2003;348(1):42-49.

9. Gillespie LD, Robertson MC, Gillespie WJ, Lamb SE, Gates S, Cumming $\mathrm{RG}$, et al. Interventions for preventing falls in older people living in the community. Cochrane Database Syst Rev 2009;(2):CD007146.

10. Pit SW, Byles JE, Henry DA, Holt L, Hansen V, Bowman DA. A quality use of medicines program for general practitioners and older people: a cluster randomised controlled trial. Med J Aust 2007;187(1):23-30.

11. Bell KJL, Hayen A, Macaskill P, Irwig L, Craig JC, Ensrud K, et al. Value of routine monitoring of bone mineral density after starting bisphosphonate treatment: secondary analysis of trial data. BMJ 2009;338:b2266.

12. Tools for practice: Bone mineral density - too much of a good thing? Edmonton (AB): Alberta College of Family Physicians; 2010 [cited 2011 Sep 20]. Available from: www.acfp.ca/docs10/BoneMineralDensity.pdf

James McCormack, BSc(Pharm), PharmD

Faculty of Pharmaceutical Sciences

University of British Columbia

Vancouver, British Columbia

\section{几 Canadian Society of Hospital Pharmacists Société canadienne des pharmaciens d'hôpitaux}

\section{Membership Year 2011/2012 (July 1, 2011 - June 30, 2012)}

Are you a current member of the Canadian Society of Hospital Pharmacists?

CSHP has celebrated 64 years of inspiration and leadership among a rapidly growing network of over 3000 pharmacy colleagues. As a member of CSHP, you will have access to resources and opportunities that will enhance your career and help impact the direction of healthcare in Canada. Your participation in CSHP 2015, an initiative challenging all pharmacists to improve patient medication outcomes and safety through advancing pharmacy practice excellence by the year 2015 , is a prime example.

For more information about CSHP, please visit us at www.cshp.ca. We invite you to reap the benefits of an affordable membership with CSHP.

Membership Enquiries: Please contact Membership Services

Bus.: (613) 736-9733 Ext. 222 Fax: (613) 736-5660 Email: membershipservices@cshp.ca 